\title{
CONSTITUCIONALISMO DEMOCRÁTICO E LITÍGIO ESTRATÉGICO: O CASO DO MANDADO DE INJUNÇÃO N. ${ }^{\circ} 4.733$
}

\section{DEMOCRATIC CONSTITUTIONALISM AND STRATEGIC LITIGATION: THE BRAZILIAN WRIT OF INJUNTION N. ${ }^{\circ} 4.733$ CASE}

\author{
Renata de Marins Jaber Maneiro ${ }^{1}$ \\ Eugeniusz Costa Lopes da $\mathrm{Cruz}^{2}$
}

\section{RESUMO}

A pesquisa tem por objeto o exame do MI 4.733 dentro do cenário da proposta teórica do constitucionalismo democrático. Para tanto, será analisada a relação deste com os movimentos sociais; esclarecendo-se a definição, características e possíveis impactos de um litígio estratégico. Em seguida, o trabalho percorrerá o desenvolvimento dos fundamentos constitucionais de inviabilidade da integração legislativa alcunhada na citada ação, além de verificar se ainda assim há potencial para algum tipo de impacto. Finaliza-se o estudo com a inclusão do referido mandamus na categoria de litígio estratégico, bem como o apontamento dos efeitos decorrentes da sentença judicial nesse contexto.

Palavras-Chave: Constitucionalismo Democrático; Litígio Estratégico; Mandado de Injunção; Direitos Fundamentais; Liberdade de Gênero.

\begin{abstract}
This research has the aim to exam the Brazilian Writ of Injunction (MI $\mathrm{n}^{\circ} 4.733$ ) in the perspective of democratic constitucionalism. In this sense, it will be analyzed its relation with the social movements, as well as the concept of strategic litigation and its possible impacts on society. Then, the article will investigate the constitutional arguments that indicates the unfeasibility of this judicial review, likewise the possibility of this writ of injunction as a strategic litigation for up coming political deliberation in Federal Congress about the subject and its effects on Brazilian society.
\end{abstract}

Keywords: Democratic Constitutionalism; Strategic Litigation; Brazilian Writ of Injunction; Fundamental Rights; Gender Freedom.

\footnotetext{
${ }^{1}$ Mestre em Direito Público e Evolução Social - Acesso à Justiça e Efetividade do Processo, pela Universidade Estácio de Sá - UNESA-Rio Janeiro, (Brasil). Professora de Direito Processual Civil. Integrante do Grupo de Pesquisa NPJuris. E-mail: renatajaber@gmail.com

2 Mestre em Direito Público e Evolução Social - Direitos Fundamentais, pela Universidade Estácio de Sá UNESA-Rio Janeiro, (Brasil). Professor de Direito Penal. Integrante do Grupo de Pesquisa Novas Perspectivas em Jurisdição Constitucional (NPJuris). E-mail: eugeniuszcruz@gmail.com
} 


\section{INTRODUÇÃO}

Ao longo das últimas décadas, houve o início da conscientização sobre a necessidade de uma composição politicamente organizada para reivindicar direitos de igualdade perante a sociedade; razão pela qual os grupos passaram a se organizar através de movimentos sociais em combate às ideias conservadoras de uma maneira geral.

O movimento gay ganhou força nos países ocidentais, e nos Estados Unidos teve como marco a madrugada do dia 28 junho de $1969^{3}$. Nessa ocasião, um grupo de homossexuais se revoltou contra uma blitz policial em um dos principais redutos gays da cidade de Nova York, o chamado Stonewall Bar, quando seus frequentadores, cansados dos abusos sofridos pela repressão estatal, se rebelaram contra esses atos de perseguição, lamentavelmente corriqueiros àquela época.

Por iguais razões, no ano seguinte, milhares de pessoas se associaram para avançar juntas sobre as ruas de São Francisco, Los Angeles e Nova York, e celebrar o primeiro aniversário do marco social ocorrido em Stonewall como a primeira marcha gay da história. A partir de então, esse movimento vem adquirindo cada vez mais força, adeptos e simpatizantes às suas causas; além de uma tímida, porém, crescente representatividade nos cenários políticos democratizados, como consequência do pluriculturalismo e heterogeneidade das sociedades que tenham um projeto político compromissado com a consolidação dos direitos humanos.

Esse cenário remete a pesquisa ao fenômeno do constitucionalismo democrático construção teórica criada nos Estados Unidos, mas perfeitamente aplicável ao Brasil - que se desdobra, em uma de suas vertentes, no estudo da potencialidade dos movimentos sociais de interagirem e participarem, juntamente com outras instâncias do Poder instituído, do processo de atualização de sentidos e valores constitucionais.

Assim, verifica-se o crescimento globalizado de reivindicações em prol do reconhecimento de direitos aos benefícios previdenciários de companheiros, às uniões homoafetivas e adoções de crianças por casais do mesmo sexo; por outro lado, ainda são recorrentes perseguições, agressões e discriminações a essas pessoas. Em razão disso, no Brasil, foi ajuizada no âmbito do Supremo Tribunal Federal o Mandado de Injunção n. ${ }^{\circ}$ 4.733,

\footnotetext{
${ }^{3}$ Cf: The Stonewall In "where pride began". The historic Stonewall Inn. Disponível em http://www.thestonewallinnnyc.com/StonewallInnNYC/HISTORY.html. Acesso em: 18 de setembro de 2016.
} 
pela Associação Brasileira de Gays, Lésbicas, Bissexuais, Travestis e Transexuais, com a pretensão de criminalizar os atos de cunho homofóbico e transfóbico.

Pelo exposto, o artigo pretende demonstrar as características do modelo teóricoabstrato de constitucionalismo democrático e a sua relação com os movimentos sociais; posteriormente, na segunda parte, será realizado investigação sobre o que se entende por litígio estratégico e a sua potencialidade no atual contexto político; na terceira, tenciona-se analisar o writ ajuizado pela aludida associação e verificar a viabilidade, para fins de injunção, da tese de ausência de tutela legal concernente à criminalização da homofobia e transfobia; e, por derradeiro, na última parte, o mandamus será explorado sob o viés de um litígio estratégico típico do constitucionalismo democrático. Assim, a pesquisa descreve as características deste modelo teórico-abstrato para que se possa compreender a utilidade da pretensão contida no MI no 4.733 como expressão de um movimento social estrategicamente direcionado ao Judiciário.

\section{CONSIDERAÇÕES SOBRE O CONSTITUCIONALISMO DEMOCRÁTICO}

Ao longo desses 28 anos de promulgação da Constituição de 88 é possível notar o desenvolvimento de movimentos de defesa do ser humano, em especial, àqueles relativos à tutela da vida e da integridade física daqueles que lutaram contra o regime político de 1964/1985. Isso porque a presença de diversos setores da sociedade civil no processo constituinte - que tiveram como resultado um amplo rol de garantias individuais e coletivas ao lado da reconquista, à época, da possibilidade de participação política nas escolhas públicas (CITTADINO, 2002, p. 25), não foi suficiente para dar efetividade aos direitos fundamentais de certas minorias.

A partir dessa perspectiva, identifica-se um contexto social onde o nível de tolerância às diversidades de origem, raça, cor e orientação sexual são baixos e em desconformidade com os objetivos de um Estado Democrático onde são frequentes as violações aos mencionados bens jurídicos, geralmente retroalimentados por um preocupante hate speach. ${ }^{4}$ Essas transgressões se caracterizam, no atual estágio civilizatório, como afrontas aos direitos fundamentais expressos na Carta Republicana, na medida em que inviabilizam o exercício

\footnotetext{
${ }^{4}$ Cf: Brasil lidera ranking de violência contra homossexuais. Disponível em: <http://www.em.com.br/app/noticia/nacional/2014/09/22/interna_nacional, 571621/brasil-amarga-o-preco-daintolerancia-e-lidera-ranking-de-violencia-contra-homossexuais.shtml>. Acesso em 13 de dezembro de 2014.
} 
constitucional da liberdade sexual, e de identidade de gênero ${ }^{5}$, de forma a evidenciar uma cidadania de baixa intensidade, para determinados setores.

Parece previsível que com a multiplicação dessas violações, grupos representativos desses vulneráveis tenham a legítima pretensão de terem as suas escolhas, concernentes a sua esfera privada, amparadas pelo Poder Público. Assim, em certas ocasiões, minorias estigmatizadas e movimentos sociais buscam o Judiciário com a finalidade de reinterpretação da Constituição de modo sensível às suas pretensões (BUNCHAFT, 2011, p. 154).

Constatado esse panorama, parece inevitável que certas esferas do Poder, em especial, o Congresso Nacional e a Corte Constitucional, que se operam a partir da lógica dos direitos e garantias fundamentais, tenham a responsabilidade conjunta de fazer cumprir as previsões jusfundamentais estabelecidas na norma que conta com o nível máximo de validade formal, uma vez que ocupa o ápice da pirâmide normativa daqueles países que optaram pelo constitucionalismo como forma de organização político jurídica (JARAMILLO, 2013, p.11). Se somente os tribunais se colocam como protagonistas da efetivação do direito constitucional, a tendência inafastável é o esvaziamento da legitimidade democrática; pois as decisões que vinculam a sociedade não podem ter somente como base de sustentação raciocínios estritamente jurídicos, mas também devem se servir de interações e diálogos do Judiciário com os demais ramos do Poder Público, e com outras esferas da sociedade, como as associações civis, partidos políticos e movimentos sociais. Os sistemas jurídicos democráticos constitucionalizados necessitam de um Estado de Direito forte no qual as interlocuções institucionais e sociais sejam constantes e fluídas.

Ultrapassadas estas considerações iniciais, a noção que se objetiva transmitir é a de que a Constituição carece de uma ininterrupta necessidade de atualização de sentido, além do permanente reforço de sua legitimidade. No que diz respeito a esse último aspecto, segundo Post (2000, p. 2-4), o constitucionalismo democrático remete à ideia de que a constituição deve ser pensada como um ato do povo capaz de mover a sociedade, traduzido pelo ideal esculpido no preâmbulo da Constituição estadunidense de 1787 "we the people establish this constitution”.

Nesse contexto, perquirindo-se a origem da noção que aqui se desenvolve - de que o Texto Fundamental é sensível às necessidades de evolução da sociedade e aos ideais de justiça

\footnotetext{
5 A referência que se faz diz respeito às violações de direitos fundamentais de lésbicas, gays, bissexuais, travestis e transexuais, em razão do objeto de investigação da presente pesquisa ser voltado à análise do $\mathrm{MI} \mathrm{n}^{\circ} 4.733$, que tem como pano de fundo as ofensas (individuais e coletivas), os homicídios, as agressões e discriminações motivadas pela orientação sexual e/ou identidade de gênero de suas vítimas.
} 
fundamental - uma corrente de constitucionalistas progressistas norte-americanos, durante as décadas de 1960 e 1970, promoveu mudanças em relação a certos valores que não mais se coadunavam com ideais igualitários colocados em xeque naquele período. Neste sentido, foram ajuizadas ações constitucionais que resultaram em mudanças estruturais no campo social daquele país; sendo possível citar o emblemático caso Brown v. Board of Education (347 U.S. 483. 1954), em que se obteve a declaração de inconstitucionalidade das leis estaduais que estabeleciam o regime de segregação racial de estudantes negros, os quais até então não podiam estudar com os brancos, o que possibilitou um tratamento igualitário entre os alunos da rede pública de ensino (POST e SIEGEL, 2009, p. 25). ${ }^{6}$ Ato contínuo, sucederam-se uma série de alterações de entendimento, a partir da cláusula da Equal Protection, a respeito da aplicação dos direitos e garantias fundamentais perante a justiça criminal, garantia da separação entre o Estado e a igreja, com relação a igualdade de gênero no âmbito das relações familiares e de trabalho (POST e SIEGEL 2013, p. 31).

Em contraposição ao pensamento liberal que se consolidava durante a década de 1980, o governo Reagan, com nítido víeis conservador, adotou estratégias políticas a fim de conter os ideais de igualdade na defesa dos direitos civis e políticos defendidos pela Warren Court e, posteriormente, na Burger Court. Com base na análise de documentos do Departamento de Justiça daquele país, Post e Siegel (2009, p.28) afirmam que nesse período o Governo deliberadamente se utilizou de indicações para ministros da Corte Constitucional americana para alterar o processo hermenêutico que lá se consolidava, afim de alinhar a interpretação conforme a visão institucional republicana - e evitar a concepção do direito constitucional segundo a qual este deve ser receptivo às grandes transformações sociais -; o que se convencionou chamar de philosophy of judicial restraint.

Com intuito de assumir uma posição intermediária ao pensamento liberal e conservador, a proposição denominada constitucionalismo democrático objetiva a conciliação entre a atuação do poder estatal e a participação popular nas escolhas políticas; o que provoca o inexorável reencontro entre direito e política, fazendo com que a Corte Constitucional passe a ter uma maior permeabilidade à sociedade (BARROSO, 2014, p. 44-48).

Reforçando tal ideia, Post (2000) afirma que a constituição deve ser pensada como um organismo vivo e capaz de mover a sociedade, ideia esta que traduz o Texto Fundamental como uma "agência coletiva" a pressupor uma voz comum que surge a partir do dissenso para

\footnotetext{
${ }^{6}$ Embora o julgamento do caso não tenha produzido um efeito imediato no mundo fático, é possível observar que a decisão foi um marco e serviu para produzir efeitos ao longo do tempo, conforme será esclarecido no próximo item.
} 
estabelecer e determinar os valores do autogoverno coletivo e, assim, reafirmar a legitimidade da constituição.

Sob essa mesma perspectiva, Valle afirma que essa teorização estaria em sintonia com o constitucionalismo dialógico, preconizando "uma ampliação do universo de interlocutores no processo de revelação de sentido" (2014, p.18) do texto e dos valores extraídos da Constituição. O caráter claramente valorativo do Texto Fundamental impõe um processo de atualização de sentido que se opera a partir da lógica dos direitos e garantias ali previstos em consonância com o projeto político de transformação da sociedade. Vale dizer, uma visão progressista do Judiciário sem se descurar da legitimidade democrática de suas decisões pode ser alcançada com o diálogo entre os Tribunais e as demais instituições políticas e sociais.

Essa concepção tem como eixo hermenêutico a possibilidade de garantir a interpretação em um cenário social plural, e, assim, potencializar a viabilidade de interação entre as Cortes e os movimentos sociais (BUNCHAFT, 2011, p.158). No cenário estadunidense, por exemplo, muito tem sido debatido sobre polêmicas questões relativas ao aborto, religião e direitos de gays, muitas vezes com um pano de fundo conservador que tende a conter os avanços defendidos por visões garantistas, onde realiza-se um desacordo moral inerente ao próprio Estado Democrático. ${ }^{7}$

Cabe mencionar importante movimento social de luta feminista na América do Norte, durante a década de 1970, determinante para a modificação de significados jusfundamentais com relação ao gênero. Baseadas na cláusula da Equal Protection, a citada marcha reivindicou e batalhou por um sentido reciclado dessa disposição de forma a excluir o entendimento tradicional e retrógado que resultava em tolerância a discriminações sexuais. Siegel (2006), a partir da reconstrução da história do denominado "de facto ERA"8 decorrente do movimento feminista voltado à elaboração da Equal Rights Amendment's ressalta a importância dos movimentos sociais na dinâmica de contestação, persuasão e formação de novo consenso; este último, quando alcançado, é apto a revelar novo sentido

\footnotetext{
${ }^{7}$ O mesmo fenômeno pode ser observado no âmbito do Supremo Tribunal Federal. A título de exemplo podem ser citados os seguintes casos: ADI $\mathrm{n}^{\circ} 3.510$, sobre o uso terapêutico de células tronco; $\mathrm{ADPF} \mathrm{n}^{\circ} 54$, sobre a antecipação terapêutica do parto de feto anencefálico; e o estudado MI $n^{\circ} 4.733$ sobre a criminalização de condutas homofóbicas e transfóbicas.

${ }^{8}$ Por ora, a referência ao "de facto ERA" tem por objetivo tão somente demonstrar que os movimentos sociais foram acolhidos na proposta teórica do constitucionalismo democrático como elemento impulsionador para a atualização do sentido da Constituição. Reservamos o detalhamento das características e efeitos do caso no item seguinte, tendo em vista que o "de facto ERA" nada mais é do que efeito de um litígio estratégico bemsucedido.
} 
constitucional em decorrência da redução de desacordos e conciliação entre os argumentos das mobilizações de interesses opostos.

Por conseguinte, a figura do backlash é concebida na proposta teórica de constitucionalismo democrático como algo natural; inclusive, podendo ser a alavanca inicial de estruturação do debate público sobre determinada interpretação constitucional. No ponto, cumpre esclarecer que o referido fenômeno não só pode ser concebido como um movimento de reação contrária à decisão judicial que esteja em descompasso com a vontade popular; como também pode se desenvolver durante o processo de tomada de decisão judicial, quando a Corte incorpora essa manifestação do dissenso durante o julgamento, propiciando a abertura do desejável diálogo para eventual formação de consenso. Em ambos os casos, o backlash, ao contrário de ser uma ameaça à democracia, deve ser encarado como fator natural para o alcance da legitimidade democrática (VALLE, 2013-A, p.25); assim é que "cidadãos engajados no backlash pressionam o governo a aplicar aquilo que acreditam ser o correto entendimento da Constituição" (POST e SIEGEL, 2007, p. 18).

Nota-se a importância dos movimentos sociais que têm atuado em prol de diferentes interpretações constitucionais, sobretudo, aquelas que visam o reconhecimento dos direitos inerentes a certas minorias, como é o caso do Mandado de Injunção $n^{\circ} 4.733$, que objetiva uma nova interpretação do inciso XLI, do artigo $5^{\circ}$ da Constituição de 1988, para incluir no sentido do dispositivo - que determina a punição de qualquer discriminação atentatória aos direitos e liberdades fundamentais - a necessidade da criminalização das condutas homofóbicas e transfóbicas.

Trata-se, pois, de reivindicação social que, em razão da dificuldade para a formação da maioria necessária à aprovação do projeto de lei no 122/2006 originário da Câmara dos Deputados, ${ }^{9}$ optou pelo litígio como estratégia em busca da produção de impacto judicial ou social; razão pela qual o próximo item foi destinado para realizar uma abordagem sobre a definição da strategic litigation e suas características.

\section{A RELAÇÃO ENTRE LITÍGIO ESTRATÉGICO E MOVIMENTOS SOCIAIS: UMA COMPREENSÃO VOLTADA À CRIAÇÃO DE IMPACTO JUDICIAL E/OU SOCIAL}

\footnotetext{
${ }^{9}$ O PLC n. ${ }^{\text {o }}$ 122/2006 encontra-se na Comissão de Direitos Humanos e Legislação Participativa do Senado Federal, sob relatoria do Senador Paulo Paim, desde 17.12.2012. A ex-senadora Marta Suplicy (PT-SP) apresentou uma prévia do seu parecer em maio de 2011, que não chegou sequer a ser lido.
} 
A strategic litigation, como que intuitivo, é a utilização do espaço judicial como arena de deliberação política, oportunizando o debate público acerca de algum tema constitucional atrelado a direitos fundamentais que, por conveniência, por dificuldades orçamentárias ou por ausência de formação da maioria, não tenha recebido a devida apreciação pelo Executivo ou Legislativo.

Revela-se como prática diferenciada de acesso ao Judiciário que - diferentemente da advocacia client-oriented, própria de demandas individuais que não tenham potencial para gerar efeitos externos ao processo - faz uso da denominada advocacia issue-oriented, direcionada ao avanço político-jurídico em tema constitucional de interesse de um determinado grupo social, que atua no exercício de campanhas de mobilização de cunho educativo e/ou persuasivo em torno do tema de direitos humanos, investe em lobby legislativo, busca solução alternativa de disputas, bem como, concomitantemente, apostam no Judiciário como uma via hábil para provocar as transformações sociais almejadas (CARDOSO, 2011, p. 365-366).

No mesmo sentido, Cappelletti e Garth apontam que nessas demandas os advogados “precisam também se engajar em práticas de 'lobby' e outras atividades extrajurídicas” (1988, p. 61). Cabe mencionar que o litígio estratégico se enquadra dentro da segunda onda renovatória de acesso à justiça ${ }^{10}$, caracterizando-se como ação de interesse público, seja em virtude da veiculação de assuntos ligados à implementação de políticas públicas, seja em razão da reivindicação de novos direitos; a exigir em ambos os casos uma atuação jurídica abrangente perante os braços especializados de Poder e a sociedade.

Rodriguéz-Garavito (2013, p. 3) utiliza a expressão casos estructurales para identificar processos judiciais com as seguintes características: tem por objetivo a denúncia de violação de direitos que afeta um grande número de pessoas; envolve órgãos ou departamentos do Estado responsáveis pelas falhas de políticas públicas que contribuem para a violação desses direitos; e, por fim, tem potencial para levar a medidas estruturais consistentes, v.g., em ações coordenadas destinadas a proteger toda população afetada e não somente os denunciantes específicos do caso. Importante ressaltar que o autor aborda a questão sob o viés de implementação de políticas públicas, identificando uma relação entre esses casos estruturales e o litígio estratégico (2013, p. 4).

\footnotetext{
${ }^{10}$ Em estudos sobre os problemas de acesso à Justiça, Cappelletti e Garth emitiram um relatório geral (Projeto Florença), onde desenvolvem uma nova abordagem sobre esses problemas, pontuando movimentos de reforma processual necessários ao esforço de melhorar o acesso à justiça, os quais foram denominados "ondas renovatórias"; sendo que a segunda onda é direcionada à representação dos interesses coletivos (1988, p. 49$67)$.
} 
Já no cenário norte-americano, a tática de contencioso judicial é frequentemente utilizada com o objetivo de instar o reconhecimento de direitos de minorias ou novos direitos, sobretudo a partir de interpretação da cláusula da Equal Protection. Nesse sentido, Cardoso (2012, p. 25) destaca que "na experiência do movimento pelos direitos civis nos Estados Unidos, um dos principais objetivos do litígio estratégico é a obtenção de precedentes judiciais, sendo o litígio na Supreme Court de especial interesse"; isso porque veicula a possibilidade de nova interpretação do sentido constitucional, que irá vincular as instâncias inferiores.

Em verdade, a estratégia judicial é utilizada pelos atores sociais, que se agrupam de forma organizada e articulada, como ferramenta para reivindicar a atualização do sentido da Constituição perante o Judiciário em prol da implementação ou reconhecimento de seus direitos; buscando-se a transformação social para além do caso concreto. Por isso, os movimentos sociais têm especial relevo no projeto do constitucionalismo democrático, pois demonstram-se "aptos a promover essa contestação de forma mais estruturada, seja no plano do debate anterior à judicialização, seja no domínio do contencioso judicial, através daquilo que os americanos denominam litígio estratégico" (VALLE, 2014, p. 26).

As mobilizações sociais passam, pois, a adotar também o discurso jurídico e, conforme as considerações de McCann (2009, p. 174-186), há verdadeira aproximação entre tradições distintas, à medida que surge uma afluência entre as teorias da mobilização social e da mobilização jurídica. Via de consequência, surge uma ambivalência entre a desconfiança e esperança no Direito como produto de tensão permanente: de um lado, este como um conjunto de meras promessas em relação ao futuro, ou como algo simbólico em relação ao passado; e, ao mesmo tempo, como ressignificação de identidades, como fator propício a promover transformação da realidade fática ${ }^{11}$. De toda sorte, a aposta no Direito tem prevalecido, de modo que, na maioria das vezes, as reivindicações sociais passam a ser direcionadas ao Judiciário quando não obtém êxito, de plano, nos demais Poderes. Assim ocorre por consequência da abertura das constituições contemporâneas, que passaram a desempenhar os papéis de condensar os valores políticos nucleares da sociedade, os consensos mínimos quanto às suas instituições e quanto aos direitos fundamentais nela consagrados, bem como

\footnotetext{
${ }^{11}$ Sobre a ambivalência do Direito como produto de oscilação entre a desconfiança e esperança em tensão permanente, cf.: LEMAITRE-RIPOLL, 2009. A obra aborda as relações entre movimentos sociais e Direito, a partir da análise de movimentos estudantis, feministas, LGBT (lésbicas, gays, bissexuais e transgêneros), indígenas e raciais na Colômbia.
} 
disciplinar o processo político democrático, propiciando o governo da maioria, a participação da minoria e a alternância no Poder (BARROSO, 2014, p. 14) ${ }^{12}$.

O referido deslocamento político é, portanto, fenômeno mundial. Cabe mencionar que a principal questão consiste em verificar se a via Judicial foi utilizada como estratégia de reivindicação política, visando efeitos externos ao processo, ou se foi utilizada como pretensão direta e exclusiva de garantia do direito fundamental in natura; este o ponto nodal de diferenciação entre litígio estratégico e comum. Seguindo esse raciocínio, convém ainda delinear considerações sobre o denominado impacto judicial e social, traçando-se um paralelo com os possíveis efeitos das decisões judiciais.

A expressão impacto social é utilizada por Cardoso (2011, p. 363-378) para designar os resultados pretendidos por aqueles que buscam o litígio estratégico como forma de alcançar ou caminhar para o alcance da transformação social. Por sua vez, em abordagem sobre o impacto judicial, Rodriguéz-Garavito $\left(2013,27\right.$ p) invoca a concepção construtivista ${ }^{13}$ para demonstrar que determinada decisão judicial pode gerar diversos efeitos além daqueles expressamente previstos, e para além dos grupos envolvidos. Ambos os autores estão se referindo às consequências indiretas decorrentes de uma sentença proferida, sobretudo, na conjuntura de um litígio estratégico; cuja característica principal é produzir efeitos externos ao processo.

Importante exemplo de litígio estratégico foi o que ocorreu nos Estados Unidos, decorrente da luta feminista pelo reconhecimento de direitos de igualdade de gênero; nesse caso, houve a produção de impacto judicial, o assim denominado "de facto ERA" (SIEGEL, 2006, p. 1322-1420). Destaca-se que o movimento teve em foco duas estratégias: a primeira, direcionada à alteração formal da Constituição por intermédio de emenda e, concomitante e alternativamente, a segunda, orientada à modificação do sentido constitucional por intermédio de interpretação judicial. Embora aquela não tenha obtido êxito - já que a Equal Rights

\footnotetext{
${ }^{12}$ A referência está mais voltada para as constituições de países de tradição civil law, e não propriamente aos de tradição common law, mas convém observar que é justamente essa abertura normativa que os aproxima. Sobre a crescente convergência entre esses dois sistemas, GROSSI destaca: "o sistema jurídico do Civil Law vem sofrendo uma grande crise nos seus pressupostos mais profundos, devido à osmose - cada vez mais acentuada com a área do Common Law - gerada por uma sutil erosão de velhas certezas sob o impulso do fenômeno esmagador da globalização jurídica" (2006, p. 69).

${ }^{13}$ Os adeptos da concepção construtivista defendem que os efeitos indiretos de uma decisão judicial podem ser mais importantes do que os efeitos diretos (RODRIGUÉZ-GARAVITO, 2013, p. 9). Em contraposição, a concepção neorrealista possui uma visão mais restrita, concentrando-se tão somente nos efeitos diretos e materiais das decisões judiciais; e, assim, critica uma postura mais proativa assumida pelo Judiciário, como no exemplo do caso Brown, em que a sentença judicial favorável não teve o condão de modificar de pronto a realidade (RODRIGUÉZ-GARAVITO, 2013, p. 8). No ponto, cumpre esclarecer que para os construtivistas, muito embora a referida decisão não tenha gerado o efeito imediato de dessegregação, configurou um avanço e marcou o início da modificação da percepção social entre brancos e negros (efeito simbólico indireto).
} 
Amendment's jamais veio a ser formalmente aprovada - as Cortes começaram a interpretar a décima quarta emenda (igualdade de cidadania) em favor da igualdade entre homens e mulheres. Ou seja, o "de facto ERA" pode ser identificado como um efeito material direto de modificação da interpretação do texto constitucional; efeito material indireto de aceitação pela sociedade da cláusula da Equal Protection também como um comando de vedação à discriminação em função do sexo; assim como, o efeito simbólico de criar ambiente propício ao incremento do debate público sobre questões de aborto e uniões homoafetivas.

Curioso observar que mesmo para aqueles que criticam a adoção de postura ativa no exercício do judicial review, o "de facto ERA" não foi invocado como símbolo de excesso antidemocrático; ao contrário, Sunstein, afeito ao minimalismo judicial, ao se referir sobre o caso argumenta que "a América está mais comprometida com a igualdade entre os sexos do que muitos países que a garantam expressamente em suas constituições" (apud SIEGEL, 2006, p. 1334). Tal afirmação é mais um indicativo de que a nova interpretação somente foi possível porque teve por pressuposto o alcance do novo consenso - elemento do constitucionalismo democrático, conforme mencionado no item anterior.

A análise desses litígios aponta para uma maior reflexão sobre os possíveis efeitos de uma decisão judicial no sistema jurídico pátrio, incorporando-se a concepção construtivista, sobretudo no âmbito de controle de constitucionalidade, o que provoca um novo olhar em relação ao caso do MI n. ${ }^{\circ}$ 4.733; sendo o item seguinte destinado à apreciação das teses envolvidas no referido writ.

\section{4. (IN)VIABILIDADE DA INTEGRAÇÃO LEGISLATIVA PERSEGUIDA PELO MI n. 4.733}

Inicialmente, a pretensão veiculada no mandado de injunção em análise não trouxe grandes repercussões, visto que a ordem foi denegada por decisão monocrática do Relator, com base no parecer da Procuradoria Geral da República, sob o fundamento de que "não há em jogo direito subjetivo especificamente consagrado na Carta Magna cuja fruição esteja sendo obstada pela ausência de regulamentação legal, mas sim um legítimo e bem articulado movimento em prol de uma legislação criminal” (STF, MI 4733, 2013, p. 4). No entanto, interposto agravo regimental, a Procuradoria Geral da República emitiu parecer em posição diametralmente oposta à anterior, opinando pela concessão da ordem de injunção ao argumento de que há proteção jurídica insuficiente para resguardar a prática da liberdade 
constitucional de orientação sexual e identidade de gênero contra a homofobia e transfobia condutas estas que estariam a inviabilizar e comprometer o livre desenvolvimento da personalidade - com base no artigo $5^{\circ}$, incisos XLI e XLII da Constituição, que estariam a impor o dever de proteção penal adequada aos direitos fundamentais em geral (PGR, Parecer 4.414, 2014).

Se for adotada uma visão tradicional (teoria neorrealista) ${ }^{14}$, é possível observar que os impetrantes apostam na tese da máxima efetividade do direito penal no controle dos cidadãos; e como meio apto a proteger a sociedade, a partir do clamor punitivista e do medo generalizado que pretende transformar a tutela criminal em prima ratio - ignorando-se o vetor da intervenção mínima (VASCONCELLOS, 2009, p.19). Nessa visão mais restrita, não é preciso muito esforço para concluir que a pretensão do referido mandamus, corroborada pelo Ministério Público de segunda instância, é mais uma aposta no discurso da emergência, que age com a vocação de expandir a repressão estatal para além dos limites estabelecidos pelas normas constitucionais, ao afirmar que da leitura do artigo $5^{\circ}$, inciso XLI da CRFB/88, é possível extrair-se um mandado constitucional de criminalização em duvidoso exercício hermenêutico.

Trata-se, fundamentalmente, da crença na ampliação da intervenção penal como fórmula solucionadora do descrédito e ineficiência de outros Poderes no exercício dos monitoramentos que lhes cabiam; vale dizer, a incapacidade estatal de intervenção com soluções mais políticas (legislativas ou administrativas) nas causas geradoras das novas formas de criminalidade (FERRAJOLI, 2010, p.646-647). Sanches critica o fenômeno da expansão do direito penal, que persegue uma resposta superficial às questões macrossociais, “deslocando ao plano simbólico (isto é, ao da declaração de princípios, que tranquiliza a opinião pública) o que deveria resolver-se no nível da instrumentalidade (da proteção efetiva)" (SANCHES, 2013, p. 29). Verifica-se uma simplificação das questões relativas aos preocupantes atos violentos de cunho homofóbico, e, assim, se afastando da busca de outras soluções mais eficazes, "ao provocar a superficial sensação de que, com a punição, o problema já estaria satisfatoriamente resolvido" (KARAN, 1996, p.82).

Forçoso reconhecer que o projeto de criminalização, muito embora antagônico às idéias defendidas pelos criminalistas mais progressistas, não é contrário ao previsto pela Constituição que admite expressamente a aplicabilidade do direito penal nos casos mais

\footnotetext{
${ }^{14}$ Possíveis inferências sobre uma visão mais moderna (teoria construtivista), a levar em conta estratégias que não se limitam aos efeitos judiciais diretos, serão desenvolvidas no próximo item.
} 
drásticos e lesivos à sociedade, desde que de forma proporcional e com respeito aos limites do Estado Constitucional e Democrático. Assim, a crítica ora desferida, recai sobre o fetiche da utilização do direito penal como (pseudo) solucionador dos conflitos em uma sociedade de risco, e não a pretensão da Associação Brasileira de Lésbicas, Gays, Bissexuais, Travestis e Transexuais em si.

Por sua vez, como afirmam Clève et al (2014), o uso da injunção para assegurar punições na esfera criminal de condutas homofóbicas ou transfóbicas vai frontalmente de encontro ao previsto na Lei Fundamental, dado que não há in casu direito fundamental subjetivo obstado em seu exercício pela ausência de normas positivadas no ordenamento jurídico. Ou seja: não é imprescindível a criminalização dessas condutas para o exercício da liberdade de gênero e orientação sexual. Com efeito, estão previstos no Código Penal os crimes contra a honra, integridade física, vida e patrimônio, dentre outras previsões, que absolutamente se aplicam e exercem a chamada prevenção geral contra essa forma de criminalidade.

Em que pese o artigo $5^{\circ}$, inciso XLI, da Constituição ter realizado menção expressa à punição de toda e qualquer forma discriminatória que atente contra os direitos e liberdades fundamentais, não significa que isso deva necessariamente ocorrer na esfera criminal; desprezando-se toda a construção teórica da excepcional utilização da sanção penal somente quando fracassarem ou demonstrarem-se ineficientes os outros ramos da tutela estatal, tendo em vista que o minimalismo propõe uma radical redução do poder punitivo, e que as agencias judiciais se atenham às estritas regras limitadoras desse ramo (ZAFFARONI et al, 2011, p.129).

Não parece que o citado dispositivo constitucional se caracterize como um mandado constitucional de criminalização, tal como os incisos XLII, XLIII e XLIV do consagrado artigo $5^{\circ}$ da Carta de 1988. Mais do que isso, está claro que ainda que fosse uma determinação fundamental dessa categoria, seria incabível a concessão da injunção, em observância ao princípio da legalidade formal, sob o qual se atribui ao Congresso Nacional a competência para legislar sobre esse ramo do direito (ZAFFARONI et al, 2011, p. 201-202); em consonância com a acepção da previsibilidade da intervenção do poder punitivo, assim também com o sentimento de segurança jurídica dos cidadãos (BATISTA, 2002, p. 67).

No que tange a opção afirmada no parecer Ministerial no sentido de que "será possível acolher o pedido de aplicação da lei no 7.716/89 para todas as formas de homofobia e transfobia (...)” (PGR, Parecer 4.414/2014), é inevitável a percepção de que isso representa a 
extensão do conceito de racismo para as hipóteses de crimes contra as citadas minorias, e, assim, uma vez adotada essa tese, a mesma se configuraria como "um claro exercício do que se poderia designar de panhermeneutismo" (CLÈVE et al, 2014); sem mencionar que esse tipo de interpretação se traduziria em verdadeira e odiosa prática de analogia in mallan partem, vedada na atual ordem democrática.

Outro ponto destacado no parecer da PGR seria a suposta violação à construção alemã da Üntermassverbot, que se configura quando o Estado deixa de proteger direitos mínimos consagrados pela Constituição, caracterizando a violação ao que se chama de proibição da proteção deficiente ou insuficiente (STRECK, 2009, p.91). Segundo CLÈVE et al (2014), a Procuradoria da República faz menção ao referido princípio do direito alemão de forma descontextualizada, na medida em que a tese utilizada pelo Tribunal Constitucional alemão, na ocasião da descriminalização do crime de aborto, entendeu que o Parlamento não teria liberdade para proceder de tal forma na medida em que não haveria alternativa minimamente eficaz para a proteção da vida do nascituro. O que deve ser aqui sublinhado é que essa decisão não teve o condão de endossar a criminalização de qualquer forma de conduta incompatível com os direitos fundamentais em si. Mas, sim, essa norma foi aplicada para operar no controle das ações e omissões insuficientes do Poder Público, servindo como critério para limitação de atos estatais; jamais como ferramenta de criminalização de condutas humanas por meio de provimento jurisdicional, como se pretende no caso do $\mathrm{MI} \mathrm{n}^{\circ} 4.733$.

A Suprema Corte deverá enfrentar essas questões no julgamento do Agravo Regimental interposto contra a decisão monocrática que não conheceu o writ em cotejo, havendo ponderáveis elementos para supor que o pedido será julgado improcedente; entretanto, considerado como instrumento estratégico próprio da proposta teórica de constitucionalismo democrático, outros efeitos poderão ser produzidos no seio da sociedade, a despeito daqueles decorrentes de uma sentença de procedência.

\section{O MI n. ○ $^{\circ} 4.733$ COMO LITÍGIO ESTRATÉGICO TÍPICO DO CONSTITUCIONALISMO DEMOCRÁTICO}

Como mencionado no item anterior, o fetichismo pelo direito penal não se coaduna com os anseios de um Estado Democrático de Direito; não obstante, a pretensão veiculada pela ABGLT abre o debate público para outras questões ligadas aos direitos das lésbicas, gays, bissexuais, travestis e transexuais, além de servir para pluralizar o debate na sociedade 
brasileira sobre o problema dos atos de discriminação em razão de opção sexual e identidade de gênero.

Sob a ótica do constitucionalismo democrático, cumpre esclarecer que o desafio voltado à busca de um novo sentido ao texto constitucional ganha maior relevância cada vez que, em contrapartida, encontra argumentos de contestação desse novo sentido que se pretende conferir. Como bem observa Siegel (2006, p. 1362-1366), somente a partir do momento em que o desafio começa a obter êxito é que a oposição encontra razões para iniciar o contingente de revitalização de justificativas como resposta às objeções. Ou seja: essa dinâmica de dissenso e aprimoramento do discurso tem por objetivo a persuasão argumentativa em busca da formação de um novo consenso que se pretende conferir à interpretação constitucional.

Quando as reivindicações sociais são direcionadas ao Judiciário em razão da obstrução da via legislativa própria, seria de bom alvitre encontrar fórmulas mais comparticipativas entre os Poderes e a sociedade para evitar danos à democracia; sendo certo que a proposta teórica de constitucionalismo aqui exposta tem por objetivo prático incorporar esse viés dialógico na formação da decisão judicial, como forma de facilitar a transformação por intermédio da interpretação dentro dessa dinâmica de contestação, persuasão e formação de novo consenso ${ }^{15}$.

De acordo com as lições de Friedman (1993, p. 653), a interpretação judicial da Constituição não pode ser realizada de forma monológica por juízes que estão no pedestal e impõem sua vontade sobre o povo; ao contrário, deve abranger uma discussão elaborada entre juízes e o corpo político. Interessante a observação de Gargarella (2013, p. 20, nota 11), no sentido de que existe um vínculo óbvio entre o trabalho de Friedman, de um lado, e Post e Siegel, de outro, à medida que eles se interessam em valorar e promover as relações entre a demanda judicial e a sociedade civil, centrando-se nas relações entre Poder Judiciário e movimentos sociais, especialmente aqueles comandados por grupos de minorias estigmatizadas.

Assim, o Mandado de Injunção n. $^{\circ} 4.733$ foi utilizado como instrumento de contestação para, mais uma vez, tematizar o assunto referente à discriminação de orientação sexual e identidade de gênero, e devolver a discussão à sociedade.

\footnotetext{
${ }^{15}$ Sobre como o STF vem desenvolvendo esse tipo de experimentalismo, bem como proposta de medidas para o aperfeiçoamento dessa dinâmica, cf.: VALLE et al (coord.), 2016.
} 
Ainda que o instrumento judicial escolhido tenha baixo potencial para efetivamente formar o novo consenso sobre a modificação da interpretação do inciso XLII do artigo $5^{\circ}$ da Constituição de 1988, para incluir no conceito de crimes contra a discriminação racial também aqueles contra discriminação da opção sexual, ou, ainda, novo consenso sobre a ampliação da interpretação do inciso XLI do referido dispositivo constitucional, para compreender um comando de punição criminal; é possível dizer que eventuais debates judiciais em torno do assunto podem alcunhar um relevante caráter educativo sobre a importância do acolhimento e proteção dessas minorias contra qualquer atitude violenta, inclusive a garantia do livre exercício de seus direitos civis, como o de união estável e casamento.

Enfatiza-se que estas questões não foram superadas. Inclusive, foi apresentado na Câmara dos Deputados um projeto de lei, assim denominado "Estatuto da Família", de constitucionalidade duvidosa, o qual reinaugura o debate quanto ao reconhecimento da união homoafetiva, já que prevê expressamente a união estável como sendo aquela entre o homem e a mulher ${ }^{16}$, a despeito da Interpretação Conforme à Constituição conferida pelo Supremo ao artigo 1.723 do Código Civil no julgamento da ADPF n. ${ }^{\circ}$ 132. Esta fora convertida em Ação Direta de Inconstitucionalidade e julgada conjuntamente com a ADI n. ${ }^{\circ}$ 4.277, no sentido de excluir do dispositivo supracitado "qualquer significado que impeça o reconhecimento da união contínua, pública e duradoura entre pessoas do mesmo sexo como família" (STF, ADPF $132,2011)$.

A propósito, a Suprema Corte vem sendo frequentemente levada a se manifestar sobre a interpretação ou aplicação dos direitos relativos à orientação sexual e identidade de gênero, ora por intermédio de demanda coletiva, como é o caso do writ objeto da presente pesquisa, ora através de ação direta, como nas hipóteses acima mencionadas, e até mesmo por meio de processo individual, conforme se verifica no recente Recurso Extraordinário n. ${ }^{\circ}$ 845.779. Neste último julgado, o Tribunal, por maioria, reconheceu a existência de repercussão geral da matéria voltada à possibilidade ou não de uma pessoa ser tratada socialmente como se pertencesse a sexo diverso do qual se identifica e se apresenta publicamente (STF, RE 845.779, 2014). ${ }^{17}$ Impende notar que até mesmo os litígios

\footnotetext{
${ }^{16} \mathrm{PL}$ 6583/2013, art. $2^{\circ}$ : "Para os fins desta Lei, define-se entidade familiar como o núcleo social formado a partir da união entre um homem e uma mulher, por meio de casamento ou união estável, ou ainda por comunidade formada por qualquer dos pais e seus descendentes".

${ }^{17}$ Sem adentrar no mérito quanto ao acerto ou não do reconhecimento da repercussão geral da matéria, a questão a ser julgada envolve a pretensão de indenização por danos morais decorrente de abordagem de transexual para utilizar banheiro do sexo oposto ao qual se dirigiu.
} 
individuais podem ter como pano de fundo a estratégia de reivindicação política e transformação social da realidade para além do caso concreto, em que a parte move a primeira pedra no xadrez, servindo como instrumento impulsionador de novas demandas e/ou novos julgamentos no mesmo sentido; desde que haja um liame subjetivo entre eles. Tudo isso confirma a tese de que a strategic litigation vem sendo utilizada no Brasil, sobretudo com relação ao reconhecimento de reivindicações da "causa gay", como um conjunto de demandas judiciais que têm por objetivo revitalizar e manter a discussão na sociedade.

Assim, para além da lógica de garantia do direito in natura decorrente dos efeitos materiais e diretos de uma decisão judicial, prestigia-se os seus efeitos materiais indiretos e simbólicos, os quais, de acordo com as lições de Rodriguéz-Garavito (2011, p. 1679-1680), podem ser identificados da seguinte forma: 1) materiais, são aqueles oriundos de modificações tangíveis na conduta de indivíduos ou grupos; 2) simbólicos, implicam em transformação cultural ou ideológica, uma vez que consistente na mudança das ideias, percepções e concepções sociais com relação à matéria objeto do caso; 3) diretos, são os que afetam os participantes do caso, tais como, as partes litigantes, os beneficiários e/ou os organismos estatais, todos destinatários da ordem judicial; e, 4) indiretos, referentes a toda e qualquer consequência que não esteja estipulada na sentença, razão pela qual afetam não só as partes do processo, como também outros sujeitos sociais. Importa sublinhar que a presença de um deles não exclui a de outro, ao contrário, eles podem ocorrer concomitantemente.

Dessa forma, embora defenda-se a tese de que o pedido constante do MI n. ${ }^{\circ} 4.733$ deva ser julgado improcedente não só pelos motivos expostos no item anterior, mas também porque não há qualquer indício de acomodação entre os argumentos de mobilização e contramobilização capazes de formar novo consenso e gerar nova interpretação do dispositivo constitucional invocado; assume-se uma concepção construtivista ao vislumbrar os seguintes efeitos: 1) material indireto de levar à votação o projeto de lei $\mathrm{n}^{\circ}{ }^{\mathrm{o}} 122 / 2006$, que prevê a alteração da lei n $7.716 / 89$ para a inclusão das condutas homofóbicas e transfóbicas no rol de crimes contra discriminação racial, pois essa seria a via democraticamente legítima, em que pesem as críticas acima apontadas sobre a expansão do direito penal; 2) material indireto de criação de um novo projeto de lei tão somente para majorar a pena dos crimes de homicídio e lesão corporal, o que parece mais razoável, caso aposte-se na ideia da prevenção geral da pena; 3) material indireto de evitar a aprovação do Projeto de Lei n. ${ }^{\circ}$ 6.583/2013, que pretende excluir a união homoafetiva do conceito de entidade familiar; 4) simbólico de preparar a sociedade para aceitação da opção sexual e identidade de gênero de cada qual 
indivíduo como manifestação natural da personalidade dentro da sociedade plural em que vivemos.

Portanto, é inequívoco o potencial deste writ para gerar impacto social, e nisso consiste ao fim e ao cabo uma estratégia vitoriosa da Associação de Lésbicas, Gays, Bissexuais, Travestis e Transgêneros e dos respectivos movimentos sociais de reivindicação do reconhecimento dos direitos dessas minorias.

\section{CONSIDERAÇÕES FINAIS}

Em um contexto no qual se verifica a crescente utilização do espaço judicial como palco de reinvindicações sociais, faz-se mister implementar um modelo teórico de constitucionalismo democrático que esteja afinado com tal realidade. Assim é que o projeto de Post e Siegel se adequa perfeitamente ao cenário fático brasileiro, sobretudo porque confere suporte para a estruturação da decisão judicial, a qual deverá incorporar o viés democrático.

O denominado litígio estratégico corrobora perfeitamente com essa ideia de legitimidade democrática da sentença, tendo em vista que o seu principal objetivo é promover a transformação externa ao processo a partir da tematização do assunto e devolução do debate à sociedade; em nítida produção de um diálogo social após o julgamento. Isso significa que a o novo consenso pode se formar durante o julgamento ou tão somente após; sendo que o impacto judicial ou social alcançado pela strategic litigation sempre terá o seu fundamento de validade no próprio regime democrático, porque não se descura do diálogo com os demais Poderes e a sociedade.

Como se nota, a homofobia é um mal que atinge as mais elementares noções de cidadania e está ligado a uma disfunção das estruturas da própria formação da sociedade brasileira. É uma questão a ser enfrentada e debatida com um amplo espectro de medidas que não podem se resumir a criminalização de uma conduta. Pelo contrário, o que deve ser trabalhado é o fortalecimento de vetores democráticos como a tolerância, a fraternidade e, principalmente, a liberdade, uma vez que a busca desenfreada pela punição pode representar uma ameaça ao Estado Democrático de Direito que jamais poderá se transformar em uma “democracia justiceira" armada da infalível e fictícia retórica de que a expansão penal seria a resposta a uma disfunção social muito mais complexa do que se apresenta. Assim sendo, a fuga seletiva ao direito penal é uma aparente solução fácil a mais um obscuro e tormentoso problema no contexto da sociedade brasileira. 
Em resposta à cogitação objeto do presente trabalho, conclui-se que o Mandado de Injunção n. ${ }^{\circ} 4.733$ foi impetrado como instrumento de estratégia judicial, com o objetivo maior que uma simples decisão judicial favorável, qual seja: trazer a debate público formas mais efetivas de proteção e conscientização dos direitos que envolvam gays, bissexuais, lésbicas, travestis, transgêneros e afins. Assim, espera-se que o writ seja julgado em breve e produza alguns de seus possíveis efeitos materiais indiretos e simbólicos, conforme exposto no último item.

\section{REFERÊNCIAS}

BALKIN, Jack M., Framework Originalism and the Living Constitution (October 23, 2008). Northwestern University Law Review, 2009. Disponível em http://ssrn.com/abstract=1290869, acesso em 15 de agosto de 2014.

BATISTA, Nilo. Introdução Crítica ao Direito Penal. 8. ed. Rio de Janeiro: Revan, 2002.

BARROSO, Luís Roberto. Jurisdição Constitucional: a tênue fronteira entre Direito e Política. 5 fev. 2014. Disponível em <http://www.migalhas.com.br/arquivos/2014/2/art2014020406.pdf>. Acesso em 29 de junho de 2014.

BRASIL. Projeto de Lei n. ${ }^{\circ}$ 122, de 12 de dezembro de 2006. Disponível em disponível em

<http://www.camara.gov.br/proposicoesWeb/prop_mostrarintegra?codteor=1159761\&filename= PL+6583/2013>. Acesso em 05 de dezembro de 2014.

BRASIL. Projeto de Lei n. ${ }^{\circ}$ 6.583, de 16 de outubro de 2013. Disponível em <http://www.camara.gov.br/proposicoesWeb/prop_mostrarintegra?codteor=1159761\&filename= PL+6583/2013>. Acesso em 05 de dezembro 2014.

BRASIL. Procuradoria Geral da República. Parecer 4414/2014. In: BRASIL. Supremo $\begin{array}{llllll}\text { Tribunal } & \text { Federal. } & \text { MI } & \text { AgR } & \text { 4733. } & \text { Disponível em }\end{array}$ $<$ http://www.stf.jus.br/portal/processo/verProcessoAndamento.asp?incidente=4239576>. Acesso em 07 de setembro de 2014. 
BRASIL. Supremo Tribunal Federal. ADPF 132. Pleno. Rel. Min. Ayres Britto. Julgamento: 05/05/2011. DJ: 14/10/2011. Disponível em < http://redir.stf.jus.br/paginadorpub/paginador.jsp?docTP=AC\&docID=628633>. Acesso em 05 de dezembro de 2012.

BRASIL. Supremo Tribunal Federal. MI 4.733. Decisão Monocrática. Rel. Min. Ricardo Lewandowscki. Julgamento: 23/10/2013. DJ: 25/10/2013. Disponível em < http://www.stf.jus.br/portal/processo/verProcessoAndamento.asp>. Acesso em 13 de outubro de 2014.

BRASIL. Supremo Tribunal Federal. RE 845779. Repercussão Geral. Rel. Min. Roberto Barroso. Decisão: 14/11/2014. Disponível em http://www.stf.jus.br/portal/jurisprudenciaRepercussao/verAndamentoProcesso.asp?incidente $=465$ 7292\&numeroProcesso=845779\&classeProcesso=RE\&numeroTema=778\#>. Acesso em 06 de dezembro de 2014.

BUNCHAFT, Maria Eugenia. Constitucionalismo democrático versus minimalismo judicial. In: Revista de Direito, Estado e Sociedade n ${ }^{o} 38$, jan-jun 2011. p.154-180.

CAPPELLETTI, Mauro \& BRYANT, Garth. In NORTHLEET, Ellen Gracie [trad]. Acesso à Justiça. Porto Alegre: Fabris, 1988 (2002).

CARDOSO, Evorah Lusci Costa. Ciclo de Vida do Litígio Estratégico no Sistema Interamericano de Direitos Humanos: dificuldades e oportunidades para atores não estatais. Revista Electrónica del Instituto de Investigaciones "Ambrosio L. Gioja" - Año V, Número Especial, 2011.

Cortes Supremas e Sociedade Civil na América Latina: Estudo comparado Brasil, Argentina e Colômbia. São Paulo, 2012, Tese de Doutorado (resumo oficial), Universidade de São Paulo (FD-USP). Disponível em <http://www.teses.usp.br/teses/disponiveis/2/2139/tde16052013-162225/pt-br.php>. Acesso em 08 de novembro de 2014. 
CITTADINO, Gisele. Judicialização da Política, Constitucionalismo Democrático e Separação de Poderes. In: VIANNA, L. W (Org.), A Democracia e os três Poderes no Brasil. Belo Horizonte: Editora UFMG, IUPERJ/FAPERJ, 2002. p. 27-42.

CLÈVE, Clèmerson Merlim et al. Perigo da criminalização judicial e quebra do estado democrático de direito. 21 ago. 2014. Revista Consultor Jurídico. Disponível em < http://www.conjur.com.br/2014-ago-21/senso-incomum-criminalizacao-judicial-quebra-estadodemocratico-direito\#author>. Acesso em 07 de setembro de 2014.

FERRAJOLI, Luigi. Direito e razão: teoria do garantismo penal. 3 ed. São Paulo: Revista dos Tribunais, 2010.

FRIEDMAN, B. (1993), Dialogue and Judicial Review, 91 Mich. L. Rev. 577.

GARGARELLA, Roberto. El nuevo constitucionalismo dialógico, frente al sistema de los frenos y contrapesos. RATJ - Revista Argentina de Teoría Jurídica, v. 14, dez. 2013. Disponível em: <http://www.utdt.edu/ver_contenido.php?id_contenido=9173\&id_item_menu=5858>. Acesso em 08 de novembro de 2014.

GROSSI, Paolo. La Primera Lección de Derecho. Clara Álvarez Alonso [trad]. Barcelona: Marcial Pons, 2006.

JARAMILLO, Leonardo Garcia. Nota introdutória. In: POST, Robert e SIEGAL, Reva. Constitucionalismo democrático. Por una reconcilliación entre Constitución y pueblo. Buenos Aires: SigloVeintiuno Editores, 2013.

LEMAITRE-RIPOLL, Julieta. El derecho como conjuro: fetichismo legal, violencia y movimientos sociales. Bogotá: Siglo del Hombre Editores y Universidad de los Andes, 2009.

KARAN, Maria Lúcia. A esquerda punitiva. In: Discursos sediciosos: crime, direito e sociedade. Rio de Janeiro: Relume Duramá, n. 1, ano 1, $1^{\circ}$ semestre de 1996, p.79-91. 
McCANN, Michael W.. Michael McCann and Rights at Work. In HALLIDAY, Simon; SCHMIDT, Patrick. Conducting Law and Society Research: Refletions on Methods and Practices. Cambridge: Cambridge University Press, 2009, p. 174-186. Disponível em $<$ http://ebooks.cambridge.org/chapter.jsf?bid=CBO9780511609770\&cid=CBO9780511609770A0 23>. Acesso em 09 de novembro de 2014.

POST. Robert. "Democratic Constitucionalism and Cultural Heterogeneity". In: University of California at Berkeley School of Law. (Working Paper No.21, 2000). Disponível em: <http:papers.ssrn.com/paper.taf?abstract_id=229161>. Acesso em 24 de abril de 2014.

POST, Robert e SIEGEL, Reva. Roe Rage: Democratic Constitutionalism and Backlash. Harvard Civil Rights-Civil Liberties Law Review, 2007; Yale Law School, Public Law Working Paper No. 131. Disponível em: <http://ssrn.com/abstract=990968>. Acesso em 28 de outubro de 2014.

. Democratic constitutionalism. In: BALKIN, Jack M. e SIEGAL, Reva B. The Constitution in 2020, USA: Oxford University Press, 2009. Disponível em: <http://www.constitution2020.org/chapters/3_Democratic\%20Constitutionalism.pdf>. Acesso em 5 de setembro de 2014.

RODRIGUÉZ-GARAVITO, César. El activismo dialógico y el impacto de los fallos sobre derechos sociales. RATJ - Revista Argentina de Teoría Jurídica, v. 14, dez. 2013. Disponível em <http://www.utdt.edu/ver_contenido.php?id_contenido=9173\&id_item_menu=5858>. Acesso em 08 de novembro de 2014.

RODRÍGUEZ-GARAVITO, César. Beyond the courtroom: the impact of judicial activism onsocioeconomic rights in Latin America. Texas Law review, v. 89 (7), 2011, p. 16691698 .

SÁNCHEZ, José-Maria Silva. A expansão do Direito Penal: Aspectos da política criminal nas sociedades pós-industriais. $3^{\mathrm{a}}$ edição. São Paulo: Revista dos Tribunais, 2013.

VALlE, Vanice Regina Lírio do. A Construção de uma Garantia Constitucional: Compreensão da Suprema Corte Quanto ao Mandado de Injunção. Rio de Janeiro: Lumen Juris, 2005. 
Backlash à decisão do Supremo Tribunal Federal: pela naturalização do dissenso como possibilidade democrática. Texto decorrente da palestra proferida no II Seminário Internacional de Teoria das Instituições. 2013. Disponível em < https://www.academia.edu/5159210/Backlash_\%C3\%A0_decis\%C3\%A3o_do_Supremo_Tribuna 1_Federal_pela_naturaliza\%C3\%A7\%C3\%A3o_do_dissenso_como_possibilidade_democr\%C3\% A1tica>. Acesso em 25 de outubro de 2014.

. Constitucionalismo Democrático: sobre como reside no poder a aptidão para limitar a si mesmo. 2014. (mimeo).

VALLE, Vanice Regina Lírio do; GOVÊA, Carina Barbosa. Direito à moradia no Brasil e na Colômbia: uma perspectiva comparativa em favor de um construtivismo judicial. Direitos Sociais e Políticas Públicas I: XXIII Encontro Nacional do CONPEDI/UNIMOVE UFCS/Florianópolis: CONPEDI, 2014, p. 222-248.

VALLE, Vanice Regina Lírio do; PULCINELLI, Eliana; MANEIRO, Renata de Marins Jaber (coord.). Contestação, persuasão e consenso no STF: construindo um constitucionalismo democrático. Rio de Janeiro: Gramma, 2016.

VASCONCELLOS, Vinícius Gomes. Expansão do Direito Penal como resposta ao questionamento do pretenso objetivo punitivo: o desvelamento do limitado poder do controle penal. Boletim IBCCRIM (Instituto brasileiro de ciências criminais) - ano $19-\mathrm{n}^{\circ} 229$, dezembro de 2011.

ZAFFARONI, Eugênio Raul; BATISTA, Nilo; ALAGIA, Alejandro; SLOKAR, Alejandro. Direito Penal Brasileiro: primeiro volume - Teoria Geral do Direito Penal. $4^{\mathrm{a}}$ ed. Rio de Janeiro: Revan, 2011. 